\title{
CARACTERIZAÇÃO GENÉTICA DE Calophyllum brasiliense Camb. EM DUAS POPULAÇÕES DE MATA CILIAR ${ }^{1}$
}

\author{
Maria Carolina Gaspar Botrel², Anderson Marcos de Souza ${ }^{2}$, Dulcinéia de Carvalho², Sheila Isabel do \\ Carmo Pinto $^{2}$, Márcia Cristina de Oliveira Moura ${ }^{2}$ e Regiane Abjaud Estopa ${ }^{2}$
}

\begin{abstract}
RESUMO - Calophyllum brasiliense Camb. é uma espécie predominante de áreas com alta saturação hídrica, sendo comum nos ambientes cilares do sul de Minas Gerais. Com o intuito de se estudar a variabilidade genética dessa espécie, 20 indivíduos reprodutivos de C. brasiliense foram amostrados de duas populações localizadas a montante do Reservatório Hidroelétrico do Funil, localizado no Município de Lavras,MG. A análise de eletroforese isoenzimática permitiu a obtenção de 17 alelos, distribuídos entre oito locos, sendo estes representados em cinco sistemas enzimáticos: $\alpha$-esterase, $\beta$-esterase, fosfatase ácida, glutamato oxalacetato, malato desidrogenase e transaminase. Os índices de diversidade revelaram um baixo número de alelos por loco em ambas as populações $(1,75$ e 1,50). A porcentagem de locos polimórficos $(P)$ foi de $37,5 \%$ e $50 \%$ nas populações I e II, respectivamente. A heterozigosidade média observada foi de 0,119 e 0,111 e a esperada, de 0,131 e 0,112 . O número de migrantes $\left(\hat{N}_{m}\right)$ encontrado entre as populações foi de 2,70 . O tamanho efetivo estimado foi de 18 indivíduos para a população I e 19 para a II.
\end{abstract}

Palavras-chave: Isoenzimas, tamanho efetivo e variabilidade genética.

\section{GENETIC CHARACTERIZATION OF Calophyllum brasiliense Camb. IN TWO POPULATIONS OF RIPARIAN FOREST}

\begin{abstract}
Calophyllum brasiliense Camb. is a predominant species in areas with high water saturation such as the riparian forests in southern Minas Gerais State. The objective of this research was to study the genetic variability of $\boldsymbol{C}$. brasiliense populations. Twenty individuals were sampled from two populations located in Funil Dam in Lavras-MG. Isozyme eletrophoresis analysis provided evidence of 17 alleles distributed in 8 loci, which were represented in five enzymatic systems: $\alpha$-esterase, $\beta$ esterase, acid phosphatase, malate dehydrogenase and transaminase oxalacetatum glutamate. The diversity indexes showed a low number of alleles per loci in both populations, pop I (1.75) and pop II (1.50). The polymorphic loci percentage $(P)$ were $37.5 \%$ and $50 \%$ in populations I and II respectively. The mean heterozygosities were 0.119 and 0.111 , while the expected was 0.131 and 0.112 . The number of migrants $\left(\hat{N}_{m}\right)$ between populations was 2.70. The estimated effective size was 18 individuals for population I, and 19 for population II.
\end{abstract}

Keywords: Effective size, genetic variability and isozymes.

\section{INTRODUÇÃO}

O aumento na demanda de energia elétrica tem impulsionado a construção de novas usinas hidroelétricas, que modificam os ambientes ciliares e suprimem grandes faixas de vegetação, podendo levar à extinção de populações de espécies vegetais locais.

A construção da Usina Hidrelétrica do Funil (UHEFunil), localizada nos Municípios de Lavras e Perdões em Minas Gerais, acarretou alterações nos ambientes ciliares localizados nos rios Grande, das Mortes e Capivari,

\footnotetext{
${ }^{1}$ Recebido em 09.8.2004 e aceito para publicação em 05.04.2006.

${ }^{2}$ Departamento de Ciências Florestais da Universidade Federal de Lavras, 37200-000 Lavras-MG.
} 
a montante da represa. Com o enchimento do reservatório, muitas populações arbóreas foram reduzidas ou eliminadas, o que provavelmente poderá comprometer a perpetuação e sobrevivência das espécies remanescentes.

Os principais efeitos da redução e fragmentação de populações naturais são a ocorrência de endogamia, o distanciamento entre indivíduos reprodutivos, a diminuição do fluxo gênico e o aumento da divergência genética entre as populações remanescentes de espécies arbóreas. Portanto, o conhecimento da variabilidade genética nessas populações é importante para se estabelecerem estratégias de conservação das espécies e ecossistemas, além de orientar programas de coleta de material para banco de germoplasma e produção de mudas para os programas de reflorestamento.

Espécies arbóreas especialistas em "habitat" são alvo nesses estudos por serem sensíveis a alterações no ambiente, sendo mais suscetíveis a extinção local. Estudos genético-ecológicos dessas espécies vêm mostrando o efeito da antropização em populações naturais, auxiliando a definição de parâmetros genéticos mais adequados para orientar e monitorar ações que visem à conservação desses ecossistemas (KAGEYAMA et al., 1998).

Padrões da variabilidade genética de Calophyllum brasiliense Camb. podem servir de modelo para a geração de programas de revegetação e implantação de ambientes ciliares, principalmente pela sua preferência por solos com alta saturação hídrica.

A espécie C. brasiliense Camb. pertence à família Clusiaceae e é conhecida popularmente por guanandi, olandi, jacareúba (Amazônia), gulanche-carvalho, guanandi-carvalho, guanandi-cedro e landim (LORENZI, 1992). É uma espécie heliófita ou de luz difusa, característica e exclusiva das florestas pluviais localizadas sobre solos úmidos e brejosos. É encontrada tanto na floresta primária densa como em vários estágios da sucessão secundária, como capoeiras e capoeirões. Sua dispersão é ampla, porém descontínua; ocorre geralmente em grandes agrupamentos que, por vezes, chega a formar populações homogêneas. É capaz de crescer virtualmente dentro da água e até em áreas de mangue. Produz quase todos os anos grande quantidade de sementes viáveis. Floresce durante os meses de setembro a novembro, e a maturação dos frutos ocorre de abril a junho (LORENZI, 1992).
A espécie apresenta o sistema reprodutivo complexo, pois possui flores hermafroditas e masculinas em indivíduos separados ou em diferentes proporções num mesmo indivíduo. Os frutos são dispersos pela água (hidrocoria), por morcegos (quiropterocoria) ou podendo ainda cair sob a copa da árvore-mãe (autocoria) (MARQUES, 1994). Como os frutos de C. brasiliense Camb. são consumidos por várias espécies animais, favorecendo o desenvolvimento da fauna, esta espécie apresenta grande potencial na recuperação de áreas alteradas, especialmente matas ciliares.

Devido à presença dominante dessa espécie nos ambientes ciliares a montante da Usina Hidrelétrica do Funil, os objetivos deste trabalho foram quantificar a diversidade genética, determinar o fluxo gênico interpopulacional e estimar o tamanho efetivo de duas populações de C. brasiliense.

\section{MATERIAL E MÉTODOS}

\subsection{Escolha das áreas para o estudo}

Com o intuito de avaliar os impactos genéticos do enchimento da Usina Hidrelétrica do Funil nas populações naturais de $C$. brasiliense localizadas montante do lago, duas populações foram escolhidas para sua caracterização da variabilidade genética. A primeira população estudada está localizada às margens do rio Mortes, no Município de Ibituruna, MG, e a segunda no Município de Itutinga, MG, distanciadas cerca de $10 \mathrm{~km}$ (Quadro 1).

\subsection{Coleta do material biológico}

Amostras de tecidos foliares de 20 indivíduos reprodutivos foram coletadas aleatoriamente em cada uma das populações, mantendo uma distância mínima de 30 m entre as árvores, para evitar a coleta de indivíduos aparentados. Após a identificação e coleta do material biológico, as amostras foram identificadas, acondicionadas em baixa temperatura e transportadas para o Laboratório de Melhoramento Florestal e Recursos Genéticos (DCF-UFLA).

Quadro 1 - Caracterização das áreas de amostragem de Calophyllum brasiliense Camb.

Table 1 -Characterization of Calophyllum brasiliense Camb. sampling areas

\begin{tabular}{lccc}
\hline Populações & Rios & $\begin{array}{c}\text { Área } \\
\text { (hectare) }\end{array}$ & Localização * \\
\hline População I & Das Mortes & 6,0 & $090 \mathrm{D}$ \\
População II & Grande & 10,0 & $158 \mathrm{E}$ \\
\hline * Refere-se ao número da propriedade na ortofotocarta(Código: 47-01-14).
\end{tabular}


A extração de enzimas foi realizada conforme Alfenas (1998), utilizando-se a eletroforese vertical, conduzida em meio-suporte de gel de poliacrilamida no sistema descontínuo, sendo o gel de concentração a 4,0\% e o gel de separação $12,5 \%$. Para a eletroforese foi utilizada a amperagem de $10 \mathrm{~mA}$ por gel, 300 volts, tendo a corrida eletroforética duração aproximada de três horas, sendo realizada à temperatura de $4^{\circ} \mathrm{C}$. Ao término da corrida, os géis foram submetidos à coloração em enzimas específicas até o aparecimento das bandas, sendo que nesse processo foram testados nove sistemas enzimáticos (Quadro 2).

Após o surgimento das zonas codificadoras, avaliou-se a presença dos locos e dos alelos. A interpretação de cada sistema enzimático foi realizada seguindo-se os padrões descritos por Alfenas et al. (1991).

\subsection{Análises estatísticas}

A interpretação dos zimogramas permitiu a determinação dos genótipos de cada indivíduo, possibilitando estimar os parâmetros genéticos. A variabilidade genética foi caracterizada a partir das estimativas das estimativas das freqüências alélicas e dos índices de diversidade genética obtidas com o auxílio do programa BIOSYS-2 (SWOFFORD e SELANDER, 1997). A heterozigosidade observada $\left(\hat{H}_{o}\right)$ para cada loco foi obtida por $\hat{H}_{o}=1-\Sigma P_{i i}$, onde $P_{i i}=$ frequiência dos genótipos homozigotos. Adiversidade gênica esperada, ou heterozigosidade esperada $\left(\hat{H}_{e}\right)$ para cada loco, foi obtida, segundo Nei (1987) por $\hat{H}_{e}=1-\Sigma p_{i}^{2}$, onde $p_{i}=$ frequiência alélica estimada do i-ésimo alelo.

Quadro 2 - Sistemas enzimáticos testados para Calophyllum brasiliense Camb.

Table 2 - Enzymatic systems tested for Calophyllum brasiliense Camb.

\begin{tabular}{lcc}
\hline Enzima & Sigla & Referência (E.C) \\
\hline Alfa-esterase & $\alpha$-Est & EC 3.1.1.1 \\
Beta-esterase & $\beta$-Est & EC 3.1.1.1 \\
Fosfatase ácida & Acp & EC 3.1.3.2 \\
Fosfoglucomutase & Pgm & EC 2.7.5.1 \\
Fosfoglucose isomerase & Pgi & EC 5. 3.1.9 \\
Glutamato-oxaloacetato & Got & EC 2.6.1.1 \\
Leucina aminopeptidase & Lap & EC 3.4.11.1 \\
Malato desidrogenase & Mdh & EC 1.1.1.37 \\
Peroxidase & Prx & EC 1.11.1.7 \\
\hline
\end{tabular}

$\mathrm{EC}=$ Enzyme Commission
A estimativa média sobre os locos de $\hat{H}_{o}$ e $\hat{H}_{e}$ foi obtida pela média aritmética entre todos os locos analisados. A porcentagem de locos polimórficos $(\hat{P})$ foi estimada pela média aritmética do número de locos polimórficos pelo número total de locos, considerando-se como loco aquele cuja freqüência do alelo mais comum não ultrapassasse $95 \%$. O número médio de alelos por loco (Â) foi obtido pela divisão do número total de alelos pelo número total de locos. O índice de fixação de Wright $(\hat{f})$ foi estimado por $\hat{f}=1-\left(\hat{H}_{o} / \hat{H}_{e}\right)$ e sua significância, calculada a partir de 10.000 reamostragens bootstrap sobre os locos, utilizando o programa GDA de Lewis e Zaykin (2000). Esse software também foi empregado para estimar os coeficientes de coancestralidade a partir da decomposição dos componentes de variação da análise de variância das freqüências alélicas, de acordo com a metodologia proposta por Cockerham (1969).

As estimativas do fluxo gênico entre as populações foram obtidas segundo a equação proposta por Crow eAoki (1984): $\hat{N}_{m}=\left[\left(1 / \hat{F}_{S T}\right)-1\right] / 4 \alpha$, em que $\alpha=[n /(n-1)]^{2}$, sendo $\hat{N}_{m}$ o número de migrantes e $n$ o número de populações. O tamanho de variância foi estimado por $\hat{N}_{b}=2 \pi \hat{N}_{m}$. O tamanho efetivo $\left(\hat{N}_{e}\right)$ baseado na variâncias das freqüências alélicas dos adultos de uma simples população foi estimado por $\hat{N}_{e}=n / 1+f$, de acordo com Vencovsky (1992).

\section{RESULTADOS E DISCUSSÕES}

\subsection{Freqüências alélicas}

Dos nove sistemas enzimáticos testados, cinco foram escolhidos por apresentarem locos passíveis de interpretação. Para a estimação da variabilidade genética são apresentadas as frequiências dos 17 alelos obtidos dos oito locos das populações de $C$. brasiliense analisadas (Quadro 3).

A população I (rio das Mortes) apresentou cinco locos monomórficos dentre os oito avaliados, enquanto na população II (rio Grande) quatro dos oito locos foram monomórficos. As duas populações apresentaram perda e fixação de alelos, além da ocorrência de alelos em baixa frequiência. Na população I, o alelo 1 mostrouse fixado nos locos $\beta$-Est-2, Got-1 e Mdh-2, enquanto o alelo 2 apresentou fixação nos $\operatorname{locos} \alpha$-Est- 1 e $\beta$ Est-1. Na população II, quatro alelos apresentaramse fixados; o alelo 1 nos locos Got-1 e Mdh-2 e o alelo

R. Árvore, Viçosa-MG, v.30, n.5, p.821-827, 2006 
2 nos locos Acp-2 e Mdh-1. Comparando as duas populações, verificou-se a ocorrência de alelos exclusivos na população I, como pode ser visto nos locos Acp1, Acp-2 e Mdh-1, e alelos exclusivos na população II, observados nos locos $\alpha$-Est-1, $\beta$-Est- 1 e $\beta$-Est- 2 . Tal presença de alelos exclusivos ou privados pode ser um indicativo de restrição ao fluxo de genes, indicando certa diferenciação entre as populações.

Baixas freqüências alélicas foram observadas nas populações analisadas. Na população I (rio das Mortes), as menores freqüências foram do alelo 1 do loco Acp1 $(0,075)$, do alelo 3 do loco Acp2 $(0,025)$ e do alelo 1 do loco Mdh1 (0,050). Na população II (Rio Grande), as menores frequiências foram do alelo 1 do loco $\beta$ Est1 $(0,071)$ e do alelo 2 do loco $\beta$-Est2 $(0,079)$. Analisando esses resultados, observou-se que alguns alelos perdidos em uma população são detectados com baixa freqüência na outra, a exemplo do alelo 3 do loco Acp-2 e do alelo 1 do loco Mdh-1. Isso pode ser indicativo da deriva genética e permite supor que a redução no tamanho dessas populações poderá acarretar diminuição na variabilidade genética desta espécie (Quadro3).

Quadro3-Freqüências alélicas e tamanho da amostra (n) de duas populações naturais de Calophyllum brasiliense Camb.

Table 3 -Allele frequencies and sample size (n) of two natural populations of Calophyllum brasiliense Camb.

\begin{tabular}{|c|c|c|c|}
\hline \multirow[b]{2}{*}{ Loco } & \multicolumn{3}{|c|}{ Populações } \\
\hline & Alelos & I & II \\
\hline \multirow[t]{4}{*}{$\overline{\mathrm{ACP}}-1$} & 1 & 0,075 & 0,250 \\
\hline & 2 & 0,725 & 0,750 \\
\hline & 3 & 0,200 & 0,000 \\
\hline & $\mathrm{n}$ & 20 & 20 \\
\hline \multirow[t]{4}{*}{$\overline{\mathrm{ACP}-2}$} & 1 & 0,175 & 0,000 \\
\hline & 2 & 0,800 & 1,000 \\
\hline & 3 & 0,025 & 0,000 \\
\hline & $\mathrm{n}$ & 20 & 13 \\
\hline \multirow[t]{2}{*}{ GOT-1 } & 1 & 1,000 & 1,000 \\
\hline & $\mathrm{n}$ & 7 & 11 \\
\hline \multirow[t]{3}{*}{$\overline{\text { a-EST-1 }}$} & 1 & 0,000 & 0,125 \\
\hline & 2 & 1,000 & 0,875 \\
\hline & $\mathrm{n}$ & 18 & 12 \\
\hline \multirow[t]{3}{*}{ b-EST-1 } & 1 & 0,000 & 0,071 \\
\hline & 2 & 1,000 & 0,929 \\
\hline & $\mathrm{N}$ & 9 & 14 \\
\hline \multirow[t]{3}{*}{ b-EST-2 } & 1 & 1,000 & 0,921 \\
\hline & 2 & 0,000 & 0,079 \\
\hline & $\mathrm{N}$ & 14 & 19 \\
\hline \multirow[t]{4}{*}{$\overline{\mathrm{MDH}-1}$} & 1 & 0,050 & 0,000 \\
\hline & 2 & 0,850 & 1,000 \\
\hline & 3 & 0,100 & 0,000 \\
\hline & $\mathrm{N}$ & 20 & 20 \\
\hline \multirow[t]{2}{*}{ MDH-2 } & 1 & 1,000 & 1,000 \\
\hline & $\mathrm{N}$ & 20 & 20 \\
\hline Total & $\mathrm{N}$ & 14 & 12 \\
\hline
\end{tabular}

R. Árvore, Viçosa-MG, v.30, n.5, p.821-827, 2006
Observando a similaridade entre as freqüências alélicas dentro de um mesmo loco (eqüidade gênica), observase que nenhum dos locos, em ambas as populações, apresentou eqüidade gênica entre dois alelos (consideram-se similares dois alelos que apresentam frequiência entre 0,350 e 0,650), mostrando alta amplitude de variação entre as freqüências alélicas. A ausência de eqüidade gênica, segundo Frankel et al. (1996), pode indicar menor diversidade nas populações e evidenciar maior suscetibilidade à fixação e perda de alelos quando tais populações são submetidas a perturbações e gargalos genéticos. Dessa maneira, as populações I e II de C. brasiliense avaliadas neste trabalho estão sujeitas aos efeitos de deriva genética, apresentando alelos que podem ser perdidos.

\section{2 Índices de diversidade genética}

Os parâmetros estimados a partir das freqüências alélicas dos oito locos isoenzimáticos utilizados para avaliar a diversidade genética estão apresentados no Quadro 4. Nos oito locos analisados foi encontrado baixa porcentagem de locos polimórficos nas populações I e II, ou seja, 37,5 e 50\%, respectivamente. Trabalhos com populações de espécies ocorrentes em mata ciliar, como Genipa americana L. (SEBBENN et al., 1998) e Calophyllum brasiliense Camb. (KAWAGUICI e KAGEYAMA, 2001), também relataram valores de polimorfismo próximos aos aqui observados, 50 e 42,86\%, respectivamente.

O número médio de alelos por loco (Â) estimado na população I foi 1,75 e na população II, 1,50 alelos/ loco, podendo ser considerados semelhantes nas duas populações, de acordo com o desvio-padrão dessa estimativa. Os valores dessas estimativas podem ser considerados baixos, mas, se considerarem apenas os locos polimórficos, o número de alelos/loco sobe para três e dois alelos/loco polimórfico, nas populações I e II, respectivamente. Pinto et al. (2004) encontraram um número médio de alelos/loco de 2,2 e 1,8, estudando duas populações de mata ciliar de Copaifera langsdorffii Desf. Mesmo não sendo uma boa medida da variabilidade genética para comparação entre amostras de tamanhos diferentes (NEI, 1987), pois é influenciada pelo tamanho da amostragem genética (número de locos), ela dá uma idéia da riqueza alélica das populações analisadas.

Os níveis de heterozigosidade observada $(0,119$ e 0,111$)$ e esperada $(0,131$ e 0,112$)$, respectivamente nas populações I e II, estão de acordo com os encontrados 
em estudos realizados com espécies arbóreas tropicais. Comparando as medidas de heterozigosidade das duas populações, com base no desvio-padrão das estimativas nota-se que estas não diferem com relação aos níveis de heterozigosidade observada e esperada. Sebbenn et al. (1998), estudando Genipa americana L., obtiveram valores de $\hat{H}_{o}$ de 0,195 e 0,105 e $\hat{H}_{e}$ de de 0,182 e 0,149 , na análise de indivíduos adultos e plântulas, respectivamente. Em trabalhos com Copaifera langsdorffii, espécie que também ocorre nos cursos d'água, Oliveira (2000) encontrou valores de $\hat{H}_{o}$ e $\hat{H}_{e}$ de 0,483 e 0,396, respectivamente. Por sua vez, Pinto et al. (2004), também estudando Copaifera lansgdorffii em área de mata ciliar, obtiveram estimativas de $\hat{H}_{o}$ e $\hat{H}_{e}$ de 0,227 e 0,282, inferiores às descritas por Oliveira (2000). Jaeger (2004), comparando duas populações Xylopia emarginata Mart em mata de galeria, obteve valores de de $\hat{H}_{o} 0,484$ e 0,722 e $\hat{H}_{e}$ de 0,395 e 0,425, números bem mais altos do que os observados neste trabalho.

Nas populações de $C$. brasiliense analisadas, as heterozigosidades médias observadas foram inferiores às esperadas, revelando um excesso de homozigotos com relação ao esperado em Equilíbrio de HardyWeinberg. Esse excesso de homozigotos é evidenciado pelos valores positivos dos índices de fixação $(\hat{f})$ nas duas populações. No entanto, apesar dos valores positivos de $\hat{f}$, eles não evidenciam a ocorrência de endogamia, pois suas estimativas podem ser consideradas baixas e não-significativas, tendo sido obtidos valores de $\hat{f}$ iguais a 0,0916 na população
I e 0,008 na população II. Apesar de a estimativa de $\hat{f}$ na população I $(0,0916)$ não ter sido diferente de zero, ela pode estar refletindo um início de endogamia nessa população, e a ausência de significância estatística pode estar relacionada ao pequeno tamanho amostral (20 indivíduos). Valores positivos de $\hat{f}$ foram encontrados também por Kawaguici e Kageyama (2001) em indivíduos adultos de $C$. brasiliense $(0,372)$. O excesso de homozigotos também foi observado em populações naturais de outras espécies arbóreas tropicais que ocorrem em matas ciliares. Sebbenn et al (2003) obtiveram um índice de fixação alto e positivo em progênies de Genipa americana ( $\hat{f}$ igual a 0,302 ), e em populações $d e$ Copaifera langsdorffii o excesso de homozigotos foi evidenciado por um $\hat{f}$ de 0,196 (PINTO et al. 2004).

As estimativas de coancestralidade obtidas indicam ausência de endogamia dentro ( $\hat{f}=0,037)$ e para o conjunto das populações ( $\hat{F}=0,110)$, sendo não-significativos de acordo com 10.000 amostragens bootstrap. O estudo da variabilidade genética revelou um valor médio de igual a $\hat{\theta}_{p} 0,077$, significativo, no conjunto das populações, indicando que $92,3 \%$ da variabilidade genética se encontra distribuída dentro das populações de C. brasiliense.

\subsection{Fluxo gênico}

As estimativas do fluxo gênico $\left(\hat{N}_{m}\right)$ e do tamanho de vizinhança $\left(\hat{N}_{b}\right)$ foram efetuadas nas duas populações e encontram-se no Quadro 5. O número médio de migrantes por geração $\left(\hat{N}_{m}\right)$ foi de 2,70 , resultando em um tamanho de vizinhança $\left(\hat{N}_{b}\right)$ em torno de 16 indivíduos.

Quadro 4 - Variabilidade genética de duas populações naturais de Calophyllum brasiliense Camb. Table 4-Genetic variability of two natural populations of Calophyllum brasiliense Camb.

\begin{tabular}{lcc}
\hline Índices de Diversidade Genética & \multicolumn{2}{c}{ Populações } \\
\cline { 2 - 3 } & I & II \\
\hline Número médio de alelos por loco & 1,75 & $(0,190)$ \\
& $(0,370)$ & 50,0 \\
Porcentagem de locos polimórficos $(0,95)$ & 37,5 & 0,111 \\
Heterozigosidade média observada $\left(\hat{H}_{o}\right)$ & 0,119 & $(0,060)$ \\
& $(0,079)$ & 0,112 \\
Heterozigosidade média esperada $\left(\hat{H}_{e}\right)$ & 0,131 & $(0,050)$ \\
& $(0,066)$ & 0,0089 \\
Índice de fixação $(\hat{f})$ & 0,0916 & 20 \\
Tamanho da amostra $(\mathrm{n})$ & 20 &
\end{tabular}

Os números entre parênteses referem-se aos desvios-padrão. ( )=standard error. 
Quadro 5-Fluxo gênico $\left(\hat{N}_{m}\right)$ e estimativas indiretas da vizinhança $\left(\hat{N}_{b}\right)$, obtidos a partir de estimativas de divergências genética $\left(\hat{\theta}_{p}\right)$ e de populações de Calophyllum brasiliense Camb.

Table 5 - Gene flow $\left(\hat{N}_{m}\right)$, neighborhood indirect estimates $\left(\hat{N}_{b}\right)$, obtained from genetic divergence estimates $\left(\hat{\theta}_{p}\right)$ and from populations of Calophyllum brasiliense Camb.

\begin{tabular}{lcccc}
\hline Populações & $\mathrm{N}$ & $\mathrm{M}$ & $\hat{N}_{m}$ & $\hat{N}_{b}$ \\
\hline I e II & 40 & 2 & 2,7 & 16,9 \\
\hline
\end{tabular}

$\mathrm{n}=$ número de indivíduos amostrados; $\mathrm{m}$ =número de populações.

Segundo Slatkin e Barton (1989), os valores de $\hat{N}_{m}$ determinam se a deriva genética, por si só, pode produzir variabilidade genética substancial entre locais: se $\hat{N}_{m}$ for maior que 1,00, o fluxo gênico será alto o suficiente para prevenir uma diferenciação em função da deriva genética. Os valores obtidos neste estudo indicam que o fluxo gênico é suficiente para prevenir uma diferenciação populacional devido à deriva genética. Valores de fluxo gênico mostram-se bastante variáveis entre as espécies arbóreas, para Copaifera langsdorffii $\left(\hat{N}_{m}=0,79\right)$ (OLIVEIRA, 2000), e Macherium villosum $\left(\hat{N}_{m}=2,09\right)$ (GIUDICE NETO, 1999). Este último autor ressaltou que as comparações entre as espécies são pouco significativas, a não ser por demonstrar que algumas têm amplo fluxo de alelos e outras não. Isso pode ser válido para C. brasiliense Camb. pois, segundo Lorenzi (1992), a espécie apresenta uma dispersão muito ampla, porém descontínua, o que pode afetar o fluxo gênico via sementes entre essas populações.

As estimativas indiretas do tamanho de vizinhança $\left(\hat{N}_{b}\right)$ apontaram que o número de genitores que trocam alelos ao acaso está em torno de 16 indivíduos, ou seja, um número menor do que o encontrado em uma mesma unidade de área implicaria aumento da divergência entre as vizinhanças, em decorrência do incremento interno dos níveis de endogamia, alterando a estrutura genética da população em médio prazo.

\subsection{Tamanho efetivo}

O tamanho efetivo populacional é um parâmetro muito importante a ser conhecido nas atividades de coleta de sementes e conservação in situ, uma vez que trata da representatividade genética das amostras. Nas duas populações, as estimativas de $\hat{N}_{e}$ foram inferiores ao número de indivíduos amostrados. Os valores obtidos indicaram que, das 20 árvores coletadas em cada uma das populações, representam geneticamente 18 indivíduos na população I e 19 na população II. Esses resultados eram esperados, já que a equação utilizada no cálculo dessa estimativa relaciona o tamanho da amostra e o índice de fixação da população, o que resulta em menor representatividade quando há excesso de homozigotos. (Quadro 6).

Quadro 6- Tamanho efetivo $\left(\hat{N}_{e}\right)$ de duas populações naturais de Calophyllum brasiliense Camb.

Table 6-Effective size ( $\hat{N}_{e}$ ) of two natural populations of Calophyllum brasiliense Camb.

\begin{tabular}{ccc}
\hline Populações & $\mathrm{n}$ & $\hat{N}_{e}$ \\
\hline I & 20 & 18,24 \\
II & 20 & 19,59 \\
\hline
\end{tabular}

$\mathrm{n}=$ número de indivíduos amostrados.

\section{CONCLUSÕES}

A análise das freqüências alélicas e a heterozigosidade média esperada indicam haver baixa variabilidade genética dentro das populações.

O índice de fixação foi baixo e não-significativo nas duas populações, evidenciando-se a ausência de endogamia.

O estudo da estrutura genética das duas populações de Calophyllum brasiliense Camb. mostrou que a maior parte da variabilidade genética dessa espécie se encontra dentro de suas populações.

O fluxo gênico estimado entre as duas populações é suficiente para contrapor os efeitos da deriva genética.

O tamanho efetivo calculado nas duas populações foi inferior ao número de indivíduos amostrados, o que evidencia a ocorrência de homozigotos dentro delas.

\section{AGRADECIMENTOS}

Ao CNPq, pela bolsa de iniciação científica concedida ao primeiro autor.

\section{REFERÊNCIAS BIBLIOGRÁFICAS}

ALFENAS, A.C. Eletroforese de isoenzimas e proteínas afins: fundamentos e aplicações em plantas e microrganismos. Viçosa, MG: Universidade Federal de Viçosa, 1998. 574p. 
ALFENAS, A.C. et al. Eletroforese de proteínas e isoenzimas de fungos e essências florestais. Viçosa, MG: Universidade Federal de Viçosa, 1991. 242p.

COCKERHAM, C.C. Variance of gene frequencies. Evolution, v.23, p. 72-84, 1969.

CROW, J. F.; AOKI, K. Group selection for polygenic behavioral trait: estimating the degree of population subdivision. Proceedings of the National Academy of Scieinces of the United States of America v. 81, p. 6073-6077, 1984.

FRANKEL, O. H.; BROWN, A. H. D.; BURDON, J. J. The conservation of plant biodiversity. Cambridge: Cambridge University Press, 1996. 299p.

GIUDICE NETO, J.D. Estrutura genética por isoenzimas em populações naturais de Jacarnadá Paulista (Macherium villosum Vog.). 1999. $128 \mathrm{f}$. Dissertação (Mestrado em Ciências Florestais) Escola Superior de Agricultura "Luiz de Queiroz", Piracicaba, 1999.

JAEGER, P. Caracterização genética e demográfica de populações de Xylopia emarginata Mart. (Annonaceae). 2004. 113 f. Dissertação (Mestrado em Engenharia Florestal) - Universidade Federal de Lavras, Lavras, 2004.

KAGEYAMA, P.Y.; GANDARA, F. B.; SOUZA, L. M. I. Conseqüências genéticas da fragmentação sobre populações de espécies arbóreas. Série Técnica IPEF, v.12, n.32 p. 65-70, 1998

KAWAGUICI, C.B.; KAGEYAMA, P.Y. Diversidade genética de três grupos de indivíduos (adultos, jovens e plântulas) de Calophyllum brasiliense $C a m b$. em uma população de mata de galeria. Scientia Forestalis, n. 59, p. 131-143, 2001.

LORENZI, H. Árvores brasileiras: manual de identificação e cultivo de plantas arbóreas nativas do Brasil. Nova Odessa: Plantarum, 1992. 352p.

LEWIS, P. O.; ZAYKIN, D. 2000. Genetic data analysis: computer program for the analysis of allelic data. Version 1.0 (d15). Free program distributed by the authors over the internet from the GDA Home Page at http: //alleyn.eeb.uconn.edu / gda/2000 (acesso em 17/09/2003).
MARQUES, M.C.M. Estudos autoecológicos do guanandi (Calophyllum brasiliense Camb. CLUSIACEAE) em mata ciliar no município de Brotas, SP. 1994. 91 f. Dissertação (Mestrado em Biologia Vegetal) - Universidade de Campinas, Campinas.1994.

NEI, M. Molecular evolutionary genetics. New York: Columbia University, 1987. 512p.

OLIVEIRA, A.F. Estrutura genética de populações naturais de Copaifera langsdorffii Desf. a partir de isoenzimas. 2000. 114f. Dissertação (Mestrado em Engenharia Florestal) - Universidade Federal de Lavras, Lavras, 2000.

PINTO, S. I. C.; SOUZA, A. M.; CARVALHO, D. Variabilidade genética por isoenzimas em populações de Copaifera langsdorffii Desf. em dois fragmentos de mata ciliar. Scientia Forestalis, n. 65, p. 40-48, 2004.

SEBBENN, A.M.; KAGEYAMA, P.Y.; VENCOVSKY, $\mathrm{R}$. Variabilidade genética, sistema reprodutivo e estrutura genética espacial em Genipa americana L. através de marcadores isoenzimáticos.

Scientia Forestalis, n. 53, p. 15-30, 1998.

SEBBENN, A.M.; KAGEYAMA, P.Y.; VENCOVSKY, R. Conservação genética in situ e número de matrizes para a coleta de sementes em população de Genipa americana $\mathrm{L}$.

Scientia Forestalis, n. 63, p. 13-22, 2003.

SLATKIN, M.; BARTON, N. H. A comparision of three indirect methods for estimating average leves of gene flow. Evolution, v.43, n.7, p.1349-1368, 1989.

SWOFORD, D.L.; SELANDER R.B. BIOSYS-2. A computer program for the analysis of allelic variation in population genetics and biochemical systematics. Release 1,7. Chicago: Illinois Natural History Survey, 1997. 78p.

VENCOVSKY, R. Análise de variância de freqüências alélicas. Revista Brasileira de Genética, v. 15, p.53-60, 1992. Suplemento, 1. 